than a decade later, Perutz showed that it was the minute movement of the iron atom into the plane of the haem group upon binding oxygen that triggered the shape change from the deoxygenated form of the protein. He once spent an hour explaining the new mechanism to me when I was a graduate student (even though he had just published it and must have talked about it many times before), as enthusiastically as a child with a new toy.

Perutz's sometimes child-like character is the surprise in Ferry's biography. Apparently, he had a desire to be praised for his discoveries, which sometimes manifested as petulance and led to ruthlessness towards competitors. But he was equally ready to confess his blunders, which endeared him to many younger scientists. Fragile health, combined with an acute sense of his failures, may have explained his reserve, particularly around the boisterous young molecular biologists at Cambridge. Ferry avoids the poppsychology that permeates so many modern biographies, while offering insight into Perutz's temperament and behaviour.

For Ferry, one of Perutz's finest achievements was the creation in 1962 of the MRC Laboratory for Molecular Biology, which has produced an astounding number of Nobel laureates and Fellows of the Royal Society. She devotes an entire chapter to its history and to Perutz's unique, hands-off style of managing it. His skill in identifying and nurturing talent at a time when molecular biology was just starting out is one of the things that makes Perutz a central figure in modern scientific history.

Ferry doesn't end the book with Perutz's death from Merkel cell carcinoma, just days after submitting his manuscripts on the structure of the protein aggregates in Huntington's disease. Instead, she follows it with a chapter about his avocation as a writer of popular essays about science and society. This is a masterstroke, because his wise and witty writings present Perutz to us at his most candid, and so the chapter sums up the book, and the man, very nicely.

Ferry has mined gold in the lives of two of the founders of structural biology; I can't wait to see whom she tackles next. Frederick Sanger, one of only four people to win two Nobel prizes? Or how about William H. Bragg or Max von Laue?

Gregory A. Petsko is professor of biochemistry and chemistry at Brandeis University, 415 South Street, Waltham, Massachusetts 02454-9110, USA, and adjunct professor in the Department of Neurology and Center for Neurologic Diseases, Brigham \& Women's Hospital, Harvard Medical School.

\title{
One man and his molecule
}

\section{Piccole Visioni: La Grande Storia di una Molecola \\ by Marta Paterlini \\ Codice Edizioni: 2006. 263 pp. €19}

\section{Ermanno Gherardi}

Max Perutz and his 1959 model of oxygenated haemoglobin is one of the iconic images of twentieth-century biology. It encapsulates a journey that began in 1936 when, armed with a degree in chemistry from the University of Vienna, Perutz moved to Cambridge to work as John Desmond Bernal's research student on the task of solving protein structures at atomic resolution using X-ray crystallography. At the time, Bernal and his former research student, Dorothy Crowfoot Hodgkin, were probably the only two people to believe that the atomic structure of a protein was within reach - having themselves obtained promising diffraction patterns from hydrated crystals of pepsin just two years earlier. Perutz was thus charged with the responsibility of realizing Bernal's dream. A year later, he opted to work on haemoglobin, the oxygentransporting protein in red blood cells, a study that lasted for the next 60 years.

Piccole Visioni ('Small Visions'), written in Italian by Marta Paterlini, narrates the story of how Perutz arrived at the atomic structure of haemoglobin and, from there, at the finely tuned mechanism that regulates oxygen binding, transport and off-loading at its destination. The book also provides a vivid account of Perutz's life and his role in founding the Medical Research Council (MRC) Laboratory of Molecular Biology, the main institution responsible for the birth of 'new biology' in the second half of the twentieth century.

Perutz's early years in Cambridge saw him

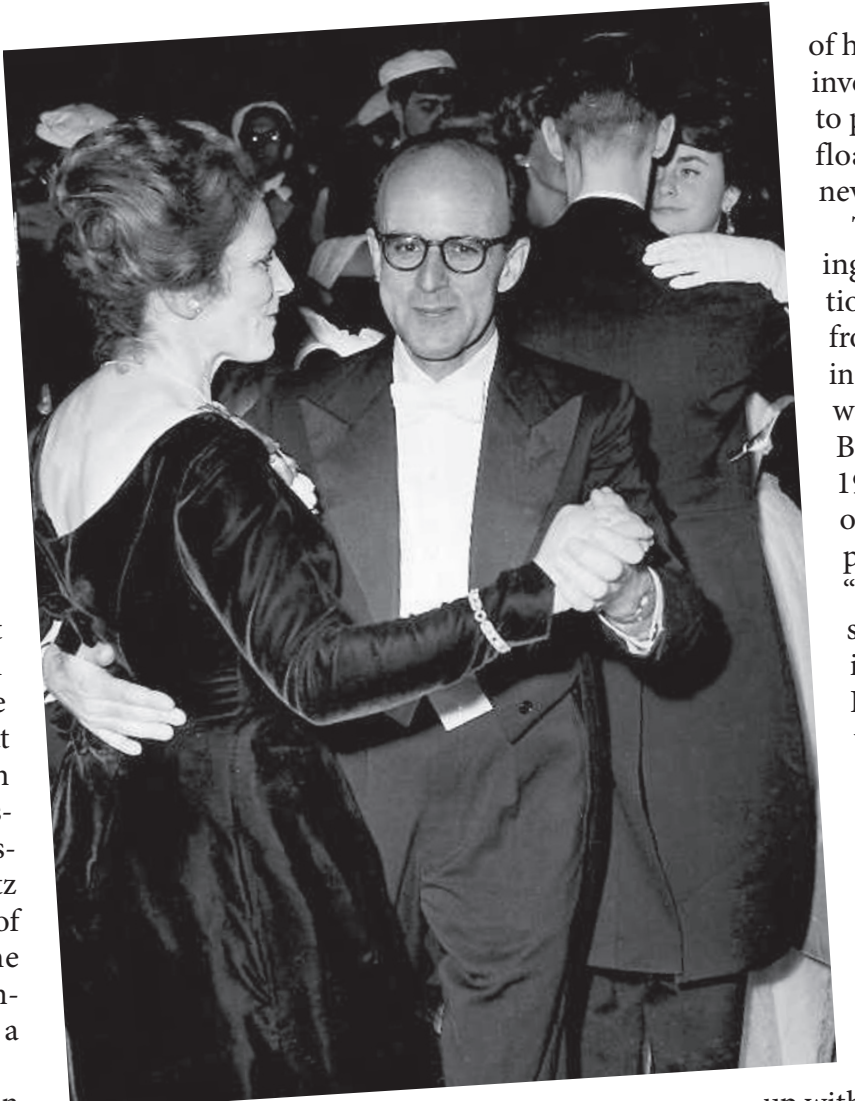

of heart - the British government involved him in a secret war project to produce reinforced ice to act as floating airfields (but which were never built).

Throughout the war years, funding from the Rockefeller Foundation in the United States and later from Imperial Chemical Industries in the United Kingdom - obtained with the help of William Lawrence Bragg, Cavendish professor from 1938 - enabled Perutz to carry on with his work. In 1947, Bragg persuaded the MRC to set up a "unit for the study of molecular structure of biological systems" involving himself, Perutz, John Kendrew and two assistants. This unit later became the present MRC Laboratory of Molecular Biology in Cambridge.

The early chapters of Piccole Visioni cover these events and introduce the basic concepts of crystallography and the problems that were faced in analysing protein crystals at the time. The rest of the book is taken up with Perutz's discovery of the basic

A glowing Perutz at the 1962 Nobel ball, with his wife Gisela.

concentrating on the crystallographic analysis of haemoglobin. He was under considerable personal strain at the time, because his parents had lost their home and property following Hitler's invasion of Austria; they arrived as refugees in Cambridge in 1939. Perutz himself, a potential 'enemy alien', was initially interned and deported to Canada until January 1941, when — in a dramatic change features of protein structure through his studies on haemoglobin. A breakthrough came in 1951, when he experimentally confirmed the structure of the $\alpha$-helix shortly after Linus Pauling had proposed its existence on theoretical grounds. Two years later, Perutz developed the technique of isomorphous replacement for protein crystallography (see 'Max in three dimensions', opposite).

Perutz's method enabled him to determine a low-resolution structure of haemoglobin and helped Kendrew to solve the structure 
of myoglobin in the late 1950s, for which they shared the Nobel Prize in Chemistry in 1962. Piccole Visioni extends these developments with an account of the subsequent higher-resolution structures of deoxygenated and oxygenated haemoglobin.

Piccole Visioni offers a lively and penetrating insight into the life and work of Perutz. Paterlini writes clearly and her book is well researched, successfully portraying both Perutz's science and his humanity, honesty and ability to reach a decision by persuasion. It has been argued that these qualities were instrumental in developing the MRC Laboratory of Molecular Biology into a highly original and successful research institution - indeed, Perutz's style of management survived his retirement as chairman of the laboratory in 1979. Perutz also played an early and important part in the genesis of the European Molecular Biology Organisation (EMBO).

Piccole Visioni does not deal with another of Perutz's legacies - namely, his writings for the public, now a commonplace initiative. $\mathrm{He}$ wrote several beautiful short essays collected in books such as Is Science Necessary? (1989), Science is Not a Quiet Life (1997) and I Wish I'd Made You Angry Earlier (1998, 2002).

Piccole Visioni is among the first of several books that address Max Perutz's gigantic contribution to twentieth-century biology and science culture. Paterlini sets the scene for these and her book will hold its place among them. I hope that it will soon become available in other languages.

Ermanno Gherardi is at the Medical Research Council Centre, Cambridge CB2 2QH, UK.

\section{Heaven in grains of sand}

\section{Nanoscientists and Tibetan monks unite to explore the mysteries of the mandala.}

\section{Martin Kemp}

Western religious art from the time of ancient Greece has generally relied on the representation of the human figure. But in many world cultures, especially those that proscribe the literal depiction of any deity, symbolic schemata and patterns have been used to express the truths of spiritual life.

Over the centuries, such patterns have evolved extraordinary levels of intricacy. Islamic tiling, famed for its remarkable mathematical symmetries, provides the most commonly cited example of age-old pattern generation that continues to engage our intellectual and aesthetic interests.

Less familiar, but no less striking, are the many Buddhist variations of the mandala, which symbolizes the Universe. The outer region of the mandala - 'that which encircles' - expresses the cosmological world system, whereas the inner zones characteristically progress to the realm of the highest deities. Dense, with map-like features, from grand structures to tiny symbolic details, mandalas serve the spiritual exercise of diligently sustained contemplation.

The most astonishing are the Tibetan mandalas composed from coloured grains of loose sand (www.imagesandmusic. $\mathrm{nl} / \mathrm{dhtml} /$ Mandala.htm\#). The time and patience required to create them is incredible to anyone involved in the frenzy of modern life. The meticulous, laborious act of making it is itself a key part of the discipline of timeless meditation. It is, as William Blake wrote, "to see heaven in a grain of sand".

This compound of extreme physica minuteness and grand cosmological structure has recently provided the rationale for the presence of a group of Tibetan monks in a leading nanotechnology laboratory. The initiative is led jointly by an artist and a chemist at the University of California in Los Angeles - Victoria Vesna from the Department of Design | Media Arts, and nanoscientist James Gimzewski from the Department of Chemistry and Biochemistry

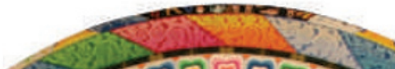

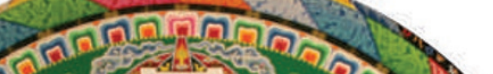

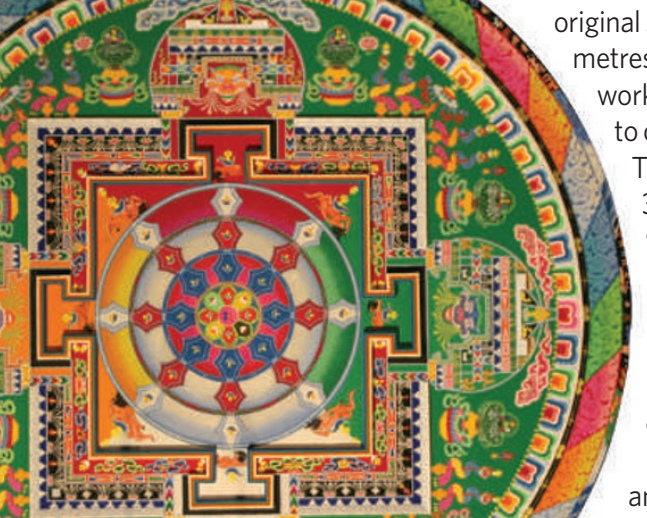
nonk

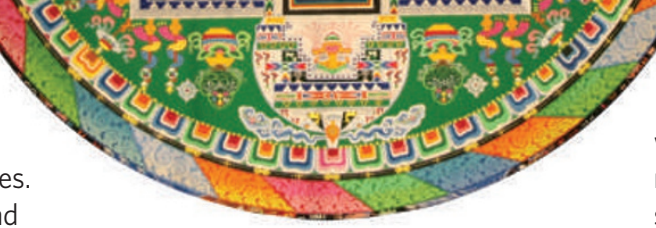

The Chakrasamvara Mandala is made of coloured sand. Its intricacies have been revealed down to the molecular level.

(see http://nano.arts.ucla.edu/mandala).

They have collaborated with monks from the Ghaden Lhopa Khangsten Monastery in India to explore a Chakrasamvara mandala. The mandala, called the 'wheel of great bliss', encircles the palatial residence of the deity Heruka Chakrasamvara. It places particular emphasis on the female ideal of wisdom.

As an extension of the monks' rendering of the cosmological whole from the tiniest grains, Gimzewski has used optical and scanning electron microscopy to delve into progressively smaller features of the sand mandala, right down to the molecular level. Microscopic images across this range were then blended with a sequence of zoomed photographs to produce a continuous visual journey from the whole mandala into everfiner details of its physical composition. The result is a seamless 15 -minute sequence that is projected onto a circular bed of flat, unpatterned sand.

The numbers involved are awesome. The original sand mandala was two-and-a-half metres in diameter and took four monks working for eight hours a day four weeks to complete in Gimzewski's laboratory. The final computer output comprised 30,000 individual frames containing 900 gigabytes of data. Thirty-six computers were pressed into service to render the images over the course of two days, and nine computers completed the recomposition of the continuous sequence.

There is something very beautiful and moving in this holy alliance of Buddhist spiritual patience, founded on minute care and untiring repetition, and the unholy processes of iteration of which modern computers are capable. The mandala-makers and the nanoscientists share the wonder of scale, involving countless parts to compose the ordered whole. We can sense the way in which religious contemplation of a time-honoured kind and modern technological science are, in their different ways, reaching out to the edges of infinity.

This is the aesthetic realm of the sublime. It is inhabited by all those who stand in awe at the wonder of the Universe and in thrall to the varied mental capacities we use to make sense of what we see and feel.

Martin Kemp is professor of the history of art at the University of Oxford, Oxford OX1 IPT, UK.

\footnotetext{
The piece is to be exhibited at the Maison Européenne de la Photographie in Paris until 30 September then at the Singapore Science Centre until 8 December 2011.
} 